\title{
Re-investigation of clino-ferrosilite from Lake Naivasha, Kenya
}

\author{
By M. G. Bown \\ Department of Mineralogy and Petrology, Cambridge
}

Summary. The clino-ferrosilite from the lithophysae in an obsidian from Lake Naivasha, Kenya, originally examined by Bowen (1935), has been shown to be substantially pure $\mathrm{FeSiO}_{3}$, with about $5 \% \mathrm{MnSiO}_{3}$ in solid solution. It has the same space-group, $P 2_{1} / c$, as clino-enstatite and pigeonite. The unit-cell dimensions are $a=9 \cdot 718 \AA, b=9 \cdot 088 \AA, c=5 \cdot 239 \AA, \beta=108^{\circ} 27^{\prime}$. These do not conform to the scheme proposed by Brown (1960): reasons are given why this was not unexpected.

\section{Introduction}

CHORTLY after experimental phase diagram work (e.g. Bowen and $\mathcal{D}$ Posnjak, 1935) had indicated that $\mathrm{FeSiO}_{3}$ could not exist as a stable compound, Bowen (1935) showed that minute needle-shaped crystals growing in the lithophysae of an obsidian from Lake Naivasha, Kenya, possessed the optical properties which would have been predicted for a monoclinic pyroxene of just this composition. The crystals were so small and so scarce that chemical analysis was not possible, and even after a thorough examination Bowen was unable to decide whether the crystals were in fact almost pure $\mathrm{FeSiO}_{3}$ which might, after all, be stable if grown at a low temperature, or whether they contained substantial amounts of other cations such as $\mathrm{Mn}$ and $\mathrm{Ti}$ which stabilized the structure and which caused mutually compensatory effects on the optical properties. In either case the name clino-ferrosilite was thought to be acceptable.

Subsequently, Richardson, Ball, and Rigby (1952) have synthesized $\mathrm{FeSiO}_{3}$ in the presence of excess $\mathrm{SiO}_{2}$ at high temperatures. They found that clino-ferrosilite was stable only between $1300^{\circ} \mathrm{C}$ and $1400^{\circ} \mathrm{C}$, but that it could persist to room temperature in the presence of excess silica, and that it was stabilized by the presence of calcium and aluminium in solid solution. Identification of the clino-pyroxene was made by $\mathrm{X}$-ray powder methods and by optical examination.

In recent years the advent of the electron micro-probe has made possible the partial chemical analysis of tiny objects, and a wide variety of pyroxenes have been examined and classified by single-crystal $\mathrm{X}$-ray 
diffraction. In the investigation here reported both these techniques were employed.

The clino-ferrosilite used came from a piece of Naivashan obsidian presented to this Department by Dr. N. L. Bowen himself. The pyroxene crystals occur as well-shaped laths elongated along the $c$-axis; a large one might be $10 \mu \times 20 \mu \times 100 \mu$ in size.

\section{Chemical composition}

The composition of Lake Naivasha clino-ferrosilite was measured by Dr. J. V. P. Long on the electron probe micro-analyser, and it is a pleasure to acknowledge my debt to him for this analysis. A clean single crystal was mounted between two grids of very fine mesh silver wire so that a natural plane face was horizontal. In the instrument used (Agrell and Long, 1959) the electron beam is incident normally upon the specimen surface and the X-rays emitted in a direction at a glancing angle of $40^{\circ}$ to the surface are collected for analysis. Manganese was the only metal found other than iron; the elements $\mathrm{Mg}, \mathrm{Al}, \mathrm{Ca}, \mathrm{Ti}, \mathrm{V}, \mathrm{Cr}, \mathrm{Co}$, and $\mathrm{Ni}$ were looked for but not detected, and the content of any one of these must certainly be less than $0.5 \mathrm{wt}$. \%. In the analysis for $\mathrm{Fe}$ and Mn pure metals were used as standards. The data were corrected for the effect of absorption and for the difference in mean atomic number between the specimen and standard. The latter correction was made according to a procedure developed by Reed (1964) which has been tested experimentally for elements up to atomic number 30 .

The analysis for Fe gave $41 \cdot 5 \pm 1.0 \mathrm{wt} . \%$; and for $\mathrm{Mn} 2 \cdot 2 \pm 0 \cdot 2 \mathrm{wt} . \%$. Assuming that both elements are present in the divalent state one obtains the equivalent contents of $\mathrm{FeSiO}_{3}$ and $\mathrm{MnSiO}_{3}$ as $98 \cdot 0 \pm 2 \cdot 3$ wt. $\%$ and $5 \cdot 2 \pm 0.5$ wt. \% respectively, totalling $103 \cdot 2 \pm 2 \cdot 8$ wt. \%. The total is rather high but the deviation from $100 \%$ is of the same order as the estimated uncertainty in the measurements. It is reasonable to assume that no other ions are present in significant quantity: the composition may then be written $\left(\mathrm{Fe}_{0.95} \mathrm{Mn}_{0.05}\right) \mathrm{SiO}_{3}$. Though not exactly pure clino-ferrosilite this is distinctly more ferriferous than the slag pyroxene of Bowen (1933), estimated to have the composition $\left(\mathrm{Ca}_{0 \cdot 08} \mathrm{Mg}_{0 \cdot 10} \mathrm{Fe}_{0 \cdot 82}\right) \mathrm{SiO}_{3}$.

\section{$X$-ray diffraction}

Despite the small size of the crystals it proved possible to obtain good quality single-crystal oscillation photographs with both iron and copper radiations, though the necessary exposure times were of the order of 
three days. These photographs confirmed that the crystals were indeed clino-pyroxene, twinned on (100) as observed optically by Bowen. It is now well known (Morimoto, 1956; Bown and Gay, 1957; Morimoto, Appleman, and Evans, 1960) that unlike the majority of clino-pyroxenes, which have space-group $C 2 / c$, clino-enstatite and pigeonite crystallize in $P 2_{1} / c$. By comparison of photographs of Lake Naivasha clinoferrosilite with indexed photographs of augite and pigeonite taken in a similar orientation it was definitely established that the clino-ferrosilite conformed to the $P 2_{1} / c$ space-group. This lower symmetry is thus possessed by the whole range of Ca-poor monoclinic pyroxenes in the $\mathrm{CaSiO}_{3}-\mathrm{MgSiO}_{3}-\mathrm{FeSiO}_{3}$ system.

Moderately accurate cell dimensions were calculated from the positions of high-angle spots on oscillation photographs. By mounting the film in the Straumanis fashion and arranging for equivalent spots to appear on either side of the $\mathrm{X}$-ray beam it was possible to determine the effective camera radius. Four $(h k 0)$ reflections from two different crystals were used to obtain $a \sin \beta$ and $b$, after which $c \sin \beta$ and $\beta$ were determined from seven $(h 0 l)$ reflections. The following results were obtained:

$$
\begin{aligned}
a \sin \beta & =9 \cdot 218 \pm 0.005 \AA & a & =9 \cdot 718 \pm 0.011 \AA \\
c \sin \beta & =4.970 \pm 0.005 \AA & b & =9 \cdot 088 \pm 0.005 \AA \\
\beta & =108^{\circ} 27^{\prime} \pm 4^{\prime} & c & =5 \cdot 239 \pm 0.007 \AA
\end{aligned}
$$

The accuracy was estimated from the reproducibility of the results from several films of each of the two crystals, and includes an allowance for the likely change had extrapolation been used. From these values the angle $(110):(110)$ is calculated as $89^{\circ} 11^{\prime}$, which is in excellent agreement with Bowen's goniometrical mean of $89^{\circ} 10^{\prime}$.

Characteristically the clino-ferrosilite needles are attached to small crystals of magnetite; as many as four needles have been seen based on the same magnetite crystal. Oscillation photographs of clino-ferrosilite crystals with magnetite still attached prove that there is a more or less definite orientation relation between the two phases, although the pyroxene crystals are frequently imperfect, showing a small range of orientations. By comparison with standard photographs and by careful measurement the orientation was found to approximate closely to $(001)_{\mathrm{cfs}}\left\|(\overline{11} 3)_{\mathrm{mag}},[010]_{\mathrm{cfs}}\right\|[110]_{\mathrm{mag}}$, that is orientation m. 2 of Bown and Gay (1959, fig. 6). Despite this the plane of contact does not seem to be $(001)_{\mathrm{cfs}}$, nor is it a $\{111\}_{\mathrm{mag}}$ plane although the magnetite is of predominantly octahedral habit. On such small crystals it is difficult to be certain of this, but it appears that the contact plane is normal to the 
length, that is the $z$-axis, of the needles. A possible explanation is that the pyroxene crystals, nucleated originally on (111) of magnetite, grew along their $z$-axes, and grew to some extent at the expense of the mag. netite.

\section{Discussion}

The optical properties of the crystals have not been newly determined. Bowen (1935) found that the measured values of $\gamma=1.794$, $\alpha=1.763( \pm 0.003)$ agreed very well with the values for pure $\mathrm{FeSiO}_{3}$ deduced by extrapolation, $\gamma=1.794, \alpha=1.760( \pm 0.003)$. He was uncertain whether to conclude that the crystals were in fact pure $\mathrm{FeSiO}_{3}$ or whether substituting ions were producing compensatory effects. The substitution of $5 \% \mathrm{Mn}$ for $\mathrm{Fe}^{2+}$ would produce only a slight decrease of refractive indices: according to the data in table 7 of Hori (1956) $\alpha$ and $\gamma$ would each be diminished by 0.002 , to give $\gamma=1.792$, $\alpha=1.758$. These values still agree with the measured ones to within the errors of measurement and extrapolation.

In the most recent publication on the cell-dimensions of common clinopyroxenes Brown (1960) suggests that for clinopyroxenes of a certain type, that is all carrying about the same amounts of minor cations, the cell dimensions $a \sin \beta$ and $b$ are given by a variation diagram equivalent to the equations

$$
\begin{aligned}
a \sin \beta & =9.030+0.30 \mathrm{fe}+0.70 \mathrm{ca}, \\
b & =8.840+0.256 \mathrm{fe}+0.12 \mathrm{ca},
\end{aligned}
$$

in which fe and ca are the ferrous and calcium ion contents expressed as fractions of the sum of the ferrous, magnesium, and calcium ion contents. Relations of this type imply that the exchange of one cation for another has the same effect upon the cell dimensions regardless of the initial composition, and that the contribution of the silicate chains is either constant or varies continuously and linearly with composition. It would. not be expected a priori that these conditions would hold for such a complex system as the clinopyroxenes, in which there are known to be two, if not three, distinct structural modifications (Morimoto, Appleman, and Evans, 1960) with different silicate chain configurations, especially as for each structure type there are two differently co-ordinated varieties of cation site between which the cations are distributed in an ordered fashion. Nevertheless the agreement between values of $a \sin \beta$ and $b$ as measured and as calculated from the above equations is, for those twenty specimens allowed by Brown (1960) to be of similar minor cation make-up, surprisingly good. The r.m.s. deviations are about 
$0.01 \AA$ for $a \sin \beta$ and $0.005 \AA$ for $b$ (that is about $4 \%$ of the difference between the greatest and least observed values in each case) while the maximum deviation in either is about $0 \cdot 02 \AA$. Of these twenty specimens however, only four contained less than $40 \% \mathrm{Ca}^{2+}$, and these were of high-temperature origin. Brown obviously realized that the Ca-poor region of his diagram might need revision when more measurements became available.

\begin{tabular}{|c|c|c|c|c|c|c|c|}
\hline & \multicolumn{4}{|c|}{ TABLE I } & \multirow[b]{2}{*}{5} & \multirow[b]{2}{*}{6} \\
\hline & & 1 & 2 & 3 & 4 & & \\
\hline \multirow{6}{*}{$a \sin \beta$} & $\mathrm{Mg}^{2+}$ & 100 & $99 \cdot 4$ & $65 \cdot 7$ & $50 \cdot 5$ & $34 \cdot 4$ & 0 \\
\hline & $\mathrm{Fe}^{2+}$ & 0 & $0 \cdot 6$ & $26 \cdot 3$ & $42 \cdot 2$ & $55 \cdot 7$ & 100 \\
\hline & $\mathrm{Ca}^{2+}$ & 0 & 0 & 8.0 & $7 \cdot 3$ & $9 \cdot 9$ & 0 \\
\hline & (calc. & $9 \cdot 030$ & $9 \cdot 032$ & $9 \cdot 165$ & $9 \cdot 208$ & $9 \cdot 266$ & $9 \cdot 330$ \\
\hline & meas. & $9 \cdot 128$ & $9 \cdot 132$ & $9 \cdot 185$ & $9 \cdot 208$ & $9 \cdot 221$ & $9 \cdot 218$ \\
\hline & diff. & -0.098 & $-0 \cdot 100$ & $-0 \cdot 020$ & 0.000 & $+0 \cdot 045$ & $+0 \cdot 112$ \\
\hline \multirow{3}{*}{$b$} & ( calc. & 8.840 & $8 \cdot 842$ & 8.917 & 8.957 & 8.994 & $9 \cdot 096$ \\
\hline & meas. & 8.828 & $8 \cdot 825$ & 8.917 & 8.959 & 8.953 & $9 \cdot 088$ \\
\hline & diff. & +0.012 & +0.017 & $0 \cdot 000$ & $-0 \cdot 002$ & +0.041 & +0.008 \\
\hline
\end{tabular}

Nos. 1, 3, and 4 are Kuno and Hess (1953) specimens 1, 2, and 3.

Nos. 2 and 5 are from Morimoto, Appleman and Evans (1960).

No. 6 is Lake Naivasha clino-ferrosilite.

Table I gives the comparison between observed and calculated $a \sin \beta$ and $b$ for several Ca-poor pyroxenes: the agreement is reasonably good for $b$, but for $a \sin \beta$ there is a pattern of discrepancies of a magnitude not readily explicable in terms of differences of minor cation content. It is suggested that a different equation is needed to approximate $a \sin \beta$ for Ca-poor clinopyroxenes, but there are not yet sufficient measurements to define this equation satisfactorily.

\section{References}

Agrell (S. O.) and Long (J. V. P.), 1959. Proc. Second Symposium on X-ray Analysis, Stockholm, p. 391.

Bowen (N. L.), 1933. J. Wash. Acad. Sci., vol. 23, p. 83.

- 1935. Amer. Journ. Sci., vol. 30, p. 481.

- and Posnjak (E.), 1935. Ibid., vol. 29, p. 151.

Bown (M. G.) and GAY (P.), 1957. Acta Cryst., vol, 10, p. 440. 1959. Amer. Min., vol. 44, p. 592.

Brown (G. M.), 1960. Ibid., vol. 45, p. 15.

HoRT (F.), 1956. Mineralogical Journal, vol. 1, p. 359.

Kuno (H.) and Hess (H. H.), 1953. Amer. Journ. Sci., vol. 251, p. 741.

Mordmoto (N.), 1956. Proc. Japan Acad., vol. 32, p. 750.

- Appleman (D. E.), and Evans (H. T.), 1960. Zeits. Krist., vol. 114, p. 120. REED (S. J. B.), 1964. Ph.D. Thesis, University of Cambridge.

Richardson (H. M.), Bati (F.), and Rigby (G. R.), 1952. Actes du IIT Congrès Céramique International, Paris, p. 173. 